\title{
Mechanical Properties of Layered-Carbon Fiber Reinforced with Vacuum Infusion Process
}

\author{
Ali Saifullah ${ }^{a}$, Moh. Jufri ${ }^{b}$, Dini Kurniawatic, Risky Chandra ${ }^{d}$ \\ a,b,c,d Universitas Muhammadiyah Malang \\ Jl. Tlogomas No. 246, Malang,Indonesia \\ 0341-464318, ext. 128 \\ e-mail: jufri@umm.ac.id
}

\begin{abstract}
Research on material engineering is widely developed in the precursors, composition of the material, and technique to create a composite. The layering and vacuum infusion resin are the developing technique to create the composites with the new characteristics and properties. This experiment is intended to find out the characteristics of layering carbon fiber reinforced by resin and is molded with vacuum infusion technique. The specimens of this experiment is layered-carbon fiber composites determined in three, four, five, six, and seven layers. The precursors of 220 and 240 carbon fibers are the main material of the composites. The tests conducted to the specimens are bending and tensile tests. The both tests are treated to reveal the mechanical properties of the composites. The least layers of 220 and 240 carbon fiber result the highest value of bending test, but the most number of carbon fiber layers show the opposite value. The results are reverse in the tensile test. The highest value of the tensile test is achieved by the most layers of carbon fiber, while the lowest value is in the least layers. This result is almost the same with the strain-stress, but overall the graphic is similarly increase to the most layers. Deduction achieved in this experiment is that the number of layers in the carbon fiber composites is significantly influencing the mechanical properties of the composite.
\end{abstract}

Keywords: bending test; layered-carbon fiber; mechanical properties; tensile test; strain-stress; vacuum infusion

\section{INTRODUCTION}

For decades, the application of carbon fiber has spread in many fields. Its properties in stiffness, lightness, and strength have lead it to a variety of "raw" materials for creating composite parts [1]. The combination of carbon fiber with other materials that have the same or different characteristics is a constituent of a composite. The composite material has its different properties from its parent materials. The combination of multi-materials gives better properties for advanced devices [2].

The development in material engineering leads the application of carbon fiber composite to penetrate in other fields. It is not limited to ready-to-use sheet materials, but it also applied in the small-size application such as energy conversion and storage devices in the form of wire [3]. In construction, carbon fiber reinforced polymer (CFRP) has proven stress and corrosion resistance. The outstanding fatigue is also proven in the strength, durability, and stability of CRFP as the stock-bridge [4]. Automotive, which mostly involved metal in the past usage has come to applied carbon fiber composite in the vehicles' body and some of the parts [5][6]. Studies have proven the properties of carbon fiber in the point of view of appearance, reinforcement, and production or manufacturing. The tensile strength or Young's modulus of the composites is not influenced by the different conditions of carbon fiber surface reinforced by polyamide 6 (PA6), but the mechanical behavior of transverse tension is influenced by the local crystalline structure of PA6 [7]. 
The composite of carbon fiber to the applications needs a specific form and characteristics based on the determined purpose. The material for the reinforcement and layering of the carbon fiber has emphasized to further study. A single carbon fiber under the torsion stress has higher tensile stress than torsion shear stress [8]. The multi-layered composites have become the development of material engineering technology. It is intended to find out the other characters for their required function. The sandwich composite of polyaramid Nomex® coated by polyimide Kapton $\AA$ treated with a uniaxial mechanical test to find out the characteristics of a woven, multi-layered, hyperelastic composite [9]. The different tests also conducted to different layers of composites composed of aluminum foam and epoxy resin face-sheet [10].

Vacuum Infusion Process (VIP) is considered effective to result reinforced carbon fiber composites. This technique is regarded not time-consuming, accurate, and needs low cost [11], [12]. A study conducted to a woven kenaf composite material with vacuum infusion technique shows the physical, mechanical, and morphological properties [13]. The parameters were determined to analyze those properties.

There has been less previous evidence for the mechanical properties of layeredcarbon fiber reinforced with resin vacuum infusion. Therefore, the mechanical properties of layered carbon fiber composites processed with vacuum infusion are studied. The layers are determined in three to seven layers and treated with bending and tensile tests.

\section{MethodS}

The mechanical properties of composites were experimented. The experiment was conducted to the precursors, $220 \mathrm{gsm}$ and $240 \mathrm{gsm}$ carbon fiber. The component of both carbon fibers are reinforced by Yukalac 157 BQTN-EX with vacuum infusion process. Each of the precursors is arranged into three, four, five, six, and seven layers before it is molded. The resin reinforcement was conducted by infusing the resin into the mold with layering carbon fiber.

The formed specimens are tested with bending and tensile tests. It is intended to determine the mechanical properties of the composites. The bending test is based on ASTM D790, while the tensile test is based on ASTM D3039. The parameter of load was treated to the specimens to measure the bending and tensile resistance. The similar parameter was also treated to different composites with different evaluation [14], [15]. The comparison of the specimens shows the best properties among them related to the tensile and bending strength.

\section{RESULT AND Discussion}

The bending strength of the carbon-reinforced composites with different type of fiber and the different number of layers shows that each specimen results different properties. The tensile and bending tests were treated to five composites. The number of layers in the specimen influences it's the bending and tensile strength.
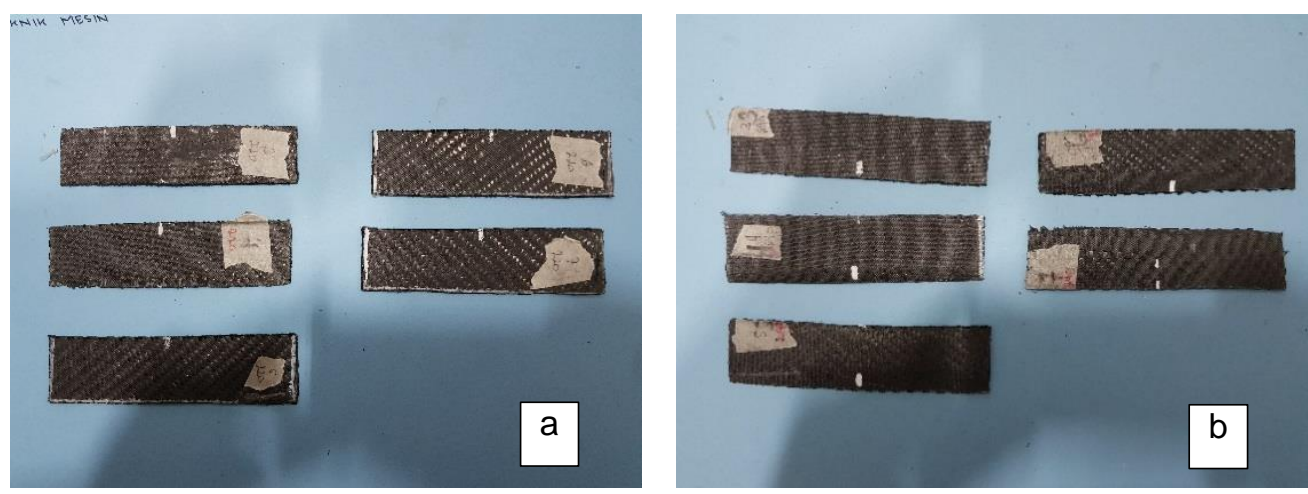

Figure 1. The bending test specimens. (a) The $220 \mathrm{gsm}$ carbon fiber, (b) the $240 \mathrm{gsm}$ carbon fiber 


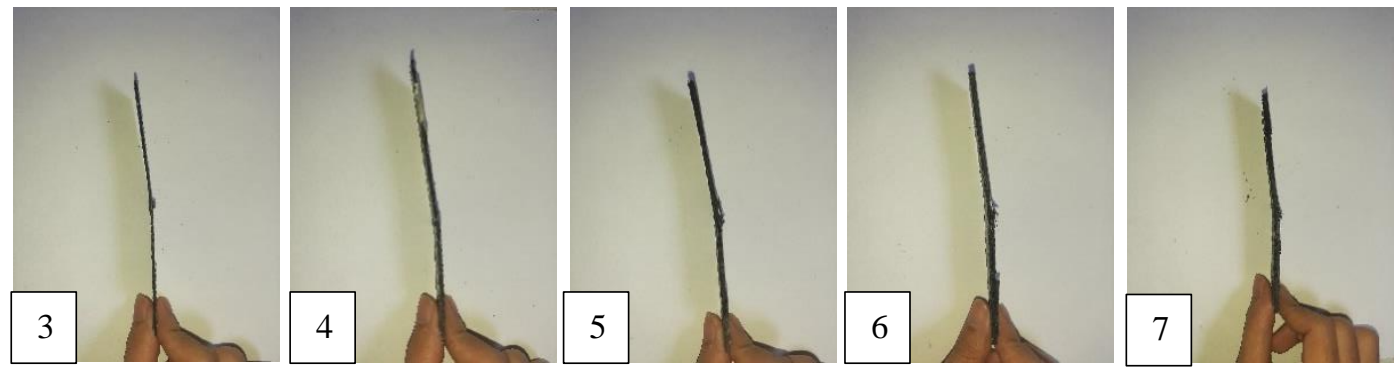

Figure 2. The result of bending test of the 220 carbon fiber specimens
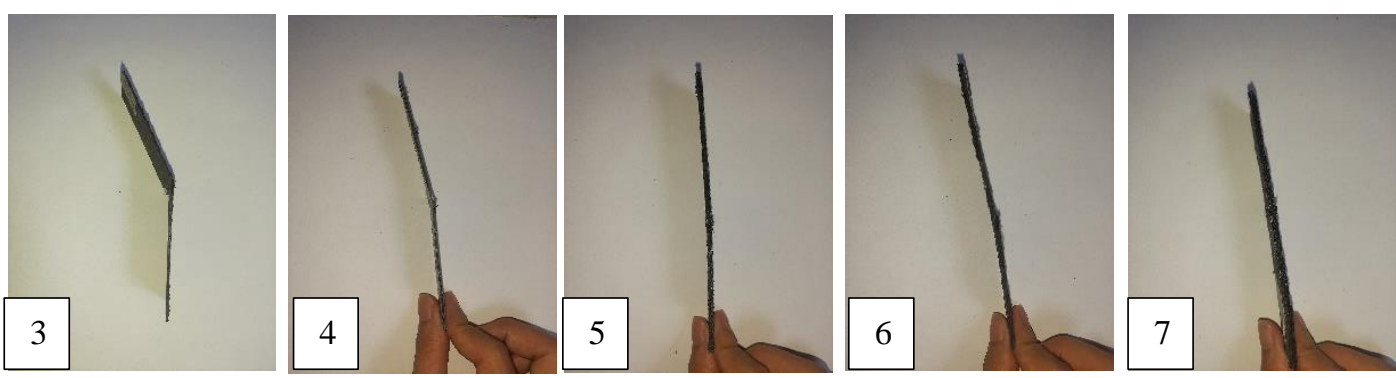

Figure 3. The result of bending test of the 240 carbon fiber specimens

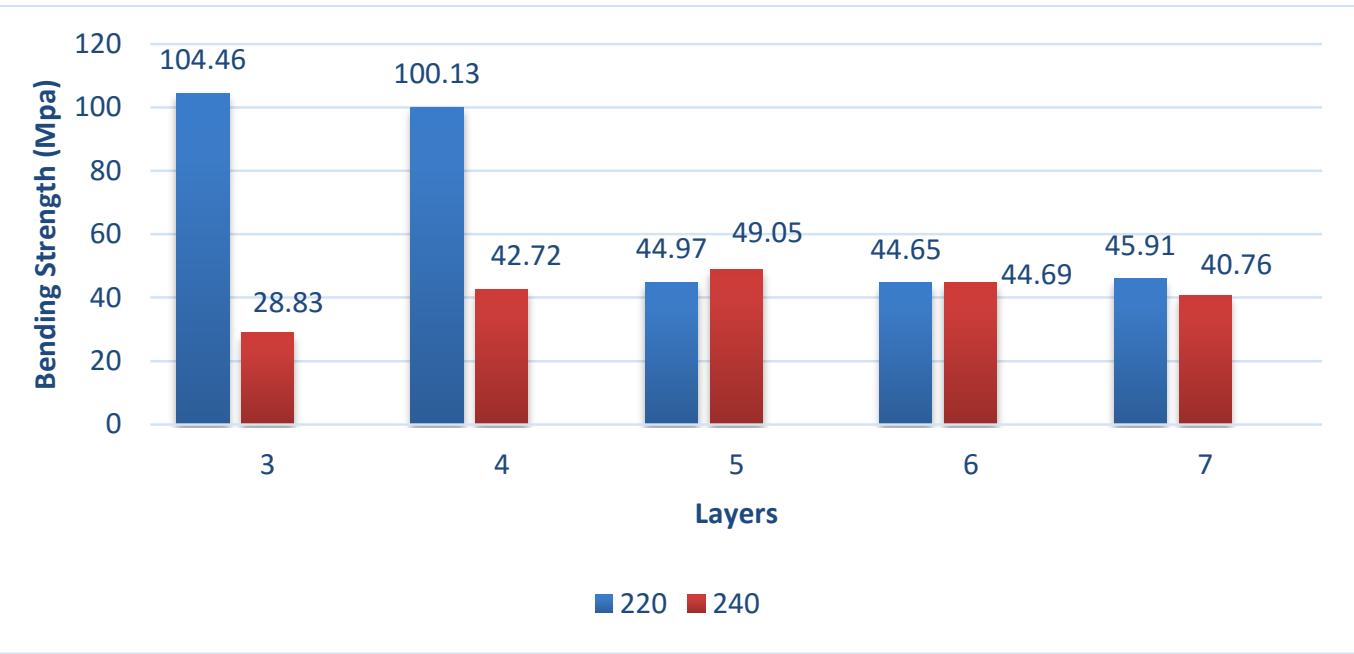

Graphic 1. The correlation of the layers and the bending strength

Different variation of bending test results occurs in the 220 carbon fiber. The number of layers significantly influences the bending strength of the specimen. The highest bending strength is achieved in the three layers of carbon fiber, while the lowest is achieved in the six layers of carbon fiber. The four layers of carbon fiber also has high value of bending strength with the slight different value with the three layers one. The wider difference occurs in the five, six, and seven layers of carbon fiber. The results of bending strength are quite different to the $240 \mathrm{gsm}$ carbon fiber. The five specimens show averagely results although there was difference among them. The three layers of carbon fiber shows the lowest bending strength and the highest is achieved by the five layers of carbon fiber. The hybrid sandwich composites reinforced by kenaf fiber without alkali treatment is able to restrain the higher bending stress. It increases when the core thickness is increase [16]. The molding time and the density of composites [17], [18]. The shortest time of molding process causes uneven thickness and different width of specimen. This results the variation of composites strength. 

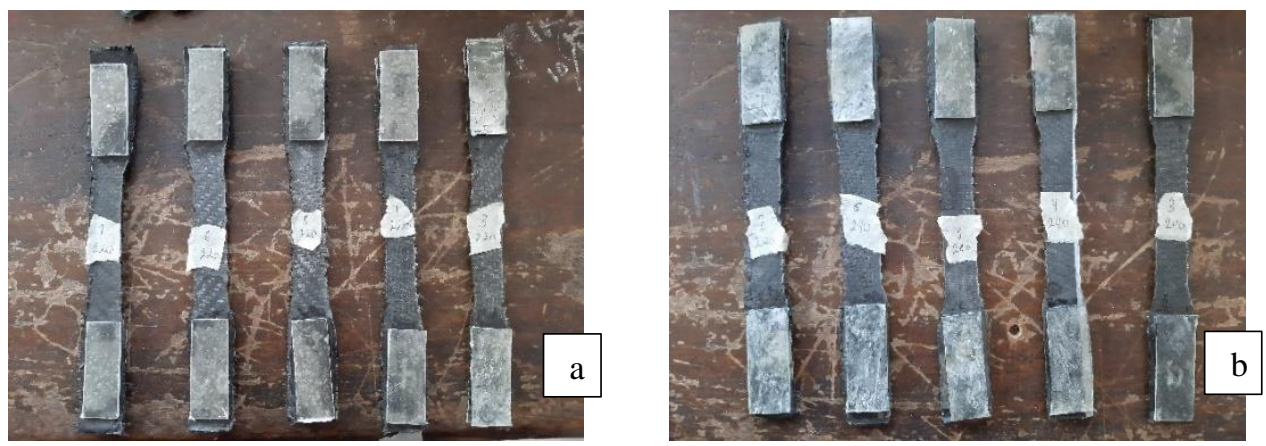

Figure 4. The tensile test specimens. (a) The $220 \mathrm{gsm}$ carbon fiber, (b) the $240 \mathrm{gsm}$ carbon fiber
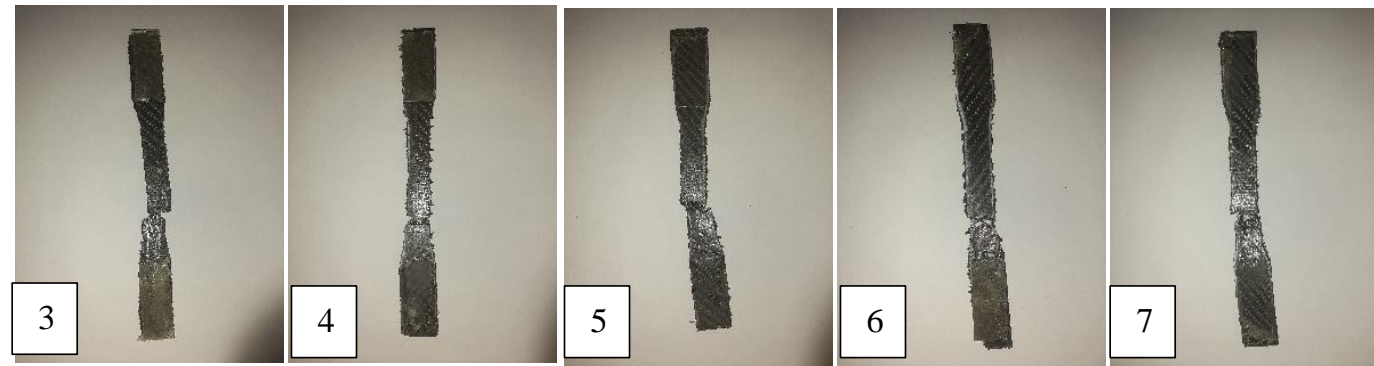

Figure 5. The result of tensile test of the 220 carbon fiber specimens
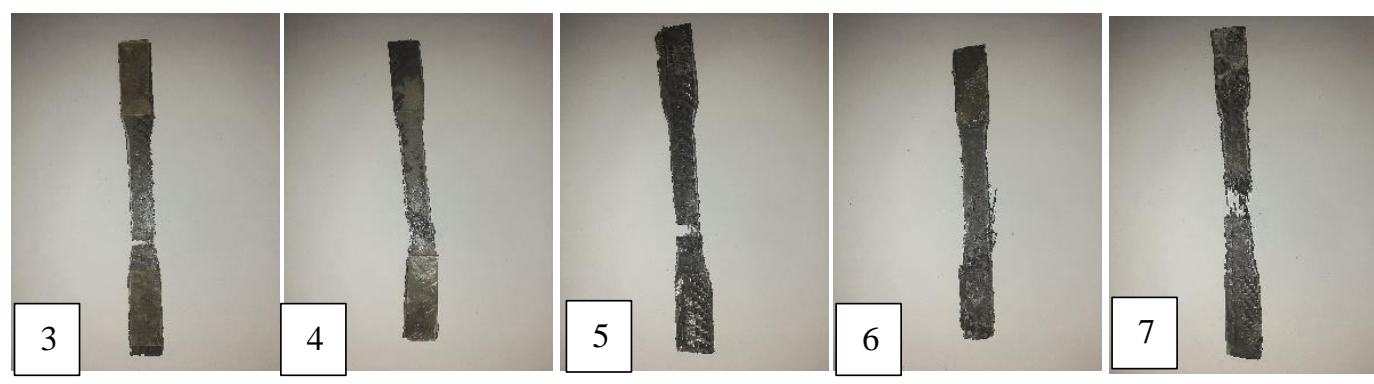

Figure 5. The result of tensile test of the 240 carbon fiber specimens

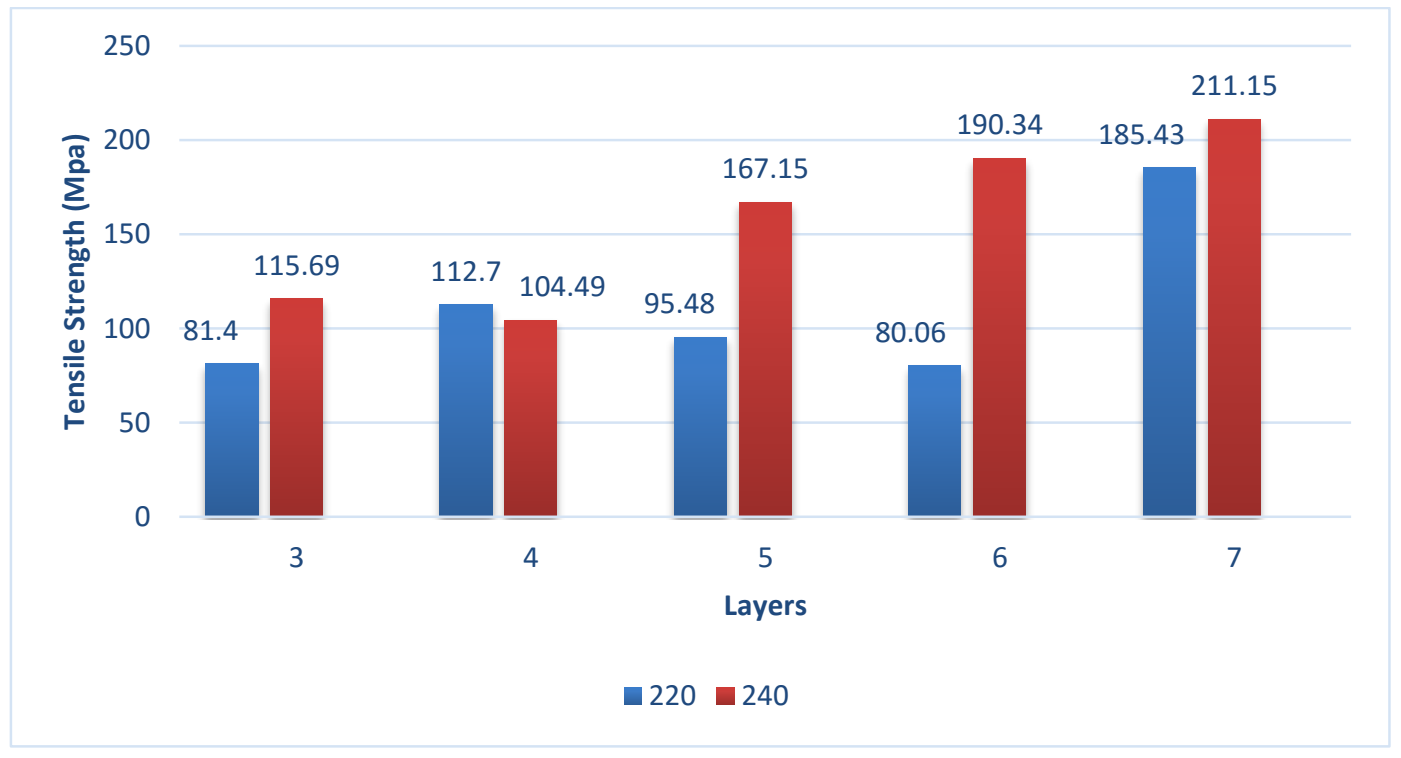

Graphic 2. The correlation of the layers and the tensile strength 
Different to the bending strength, the highest tensile strength of $220 \mathrm{gsm}$ carbon fiber is achieved by the seven layers of carbon fiber specimen. The wide difference of the tensile strength can be seen in the three, four, five, and six layers of carbon fiber specimen. The lowest tensile strength had by the six layers of carbon fiber. The tensile strength of 240 gsm carbon fiber is respectively increase in the five, six, and seven layers. The highest value of tensile strength is in the seven layers of $240 \mathrm{gsm}$ carbon fiber, while the lowest is in the four layers of carbon fiber. The tensile strength of a composites is significantly influenced by the direction of each fiber layer, the woven size, the fiber density, [7] and of course, the combination of resin as the precursors of composites.

The strain-stress needs to be measured after the bending and the tensile strength obtained. It is intended to find out that the value is directly in line with the strength value or vice versa. The strain is elongation of an object toward the initial length.

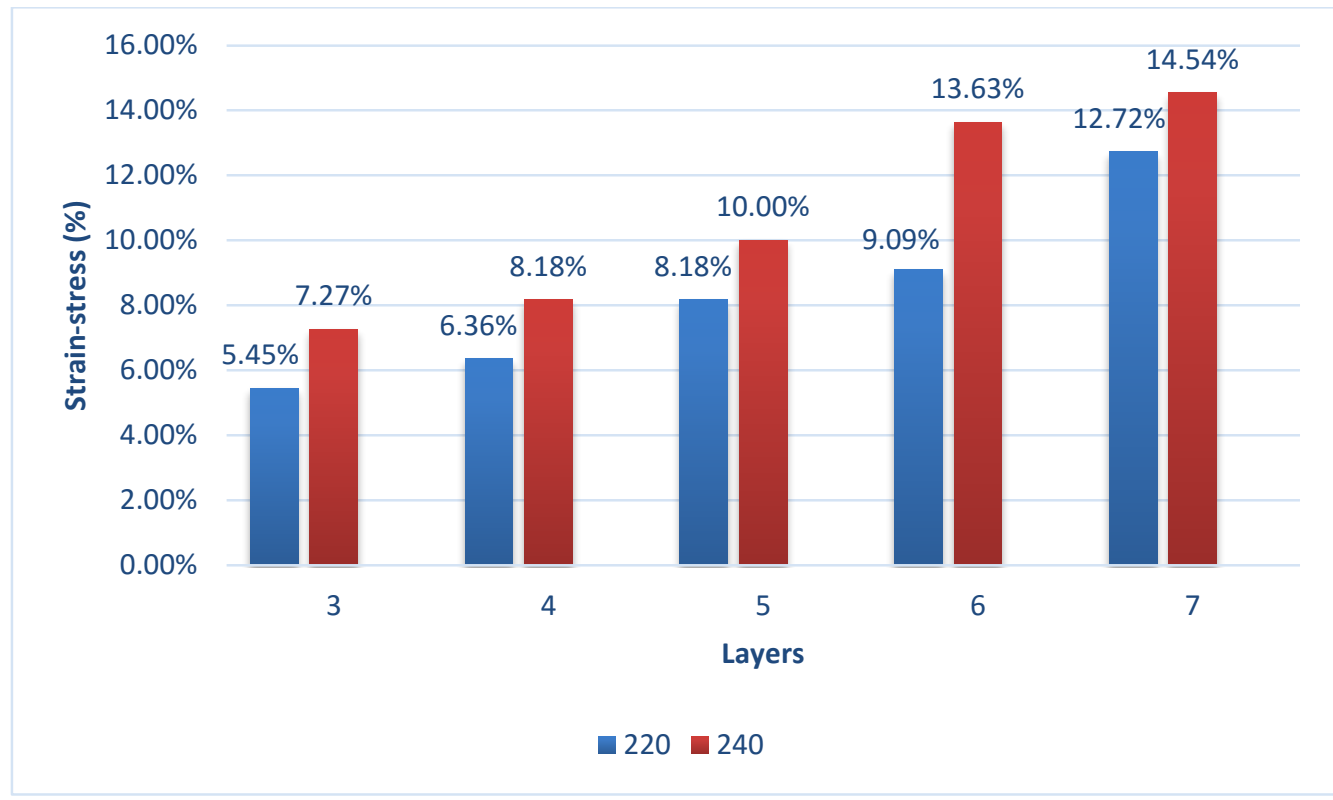

Graphic. The correlation of the layers and the strain-stress

The graphic of strain-stress of the $220 \mathrm{gsm}$ and $240 \mathrm{gsm}$ of carbon fiber show the terraces bar. The percentage shows the respectively increasing value of the strain-stress of the specimens. The lowest value resulted by the least layers.

The higher value of the tensile stress increases the strain-stress. The more flexure of composites has relatively high the strain-stress, and reversely, the more fragile of a composites the lower is its strain-stress.

The strain trend increases with increasing temperature. The highest strain is obtained at a combination of $5 \mathrm{~mm}$ fiber length and a temperature of $25^{\circ} \mathrm{C}$. This is because at low temperatures the bond between the matrix and the reinforcement becomes weak. The reason is the water vapor permeating the fibers damaging the fibers causing delamination [19], [20]. Strain increases due to the resistance response of the composite to the received tensile load so that the composite experiences stress and strain occurs as an effect of internal shifting at the atomic level on the particles that make up the composite, so that the composite experiences an increase in length or stretching. This situation greatly impacts the tensile strain value of the composite when compared to the gauge length or (Lo). The greater the value added in length $(\Delta L)$, the greater the tensile strain [21].

The lamina composite with E-glass WR fiber has a failure in the form of a matrix into small fractions and spreads in the fiber area that has the highest tensile stress, it is different 
from the carbon fiber lamina composite with the fractional matrix of the Carbon fiber lamina composite. It is not completely separated from the bond, but only on the part of the broken fiber [22]. From the research of Saputra in 2020, crack deflection occurs because the matrix is detached from the fibers, this indicates that the matrix is not strong enough to withstand the pull given during the test, therefore the dominant fracture follows the orientation of the fiber.

The causes of fractures during tensile testing, among others: in the specimen because the spread of the fibers does not spread evenly so that the strength in that part is higher than other parts. In making a specimen, a fracture can also occur, such as the presence of voids in a specimen so that the strength that occurs is reduced. In addition, fractures in the grip of the test equipment can also occur due to technical errors when conducting the test, such as clamping of the specimen when the test is too tight so that the strength in the area is high, only concentrated in the gripping area [23].

\section{CONCLUSION}

The results of bending tests of 220 carbon fiber shows the bending strength value that tends to increase. Respectively, the bending strength values of three, four, five, six, and seven layers of carbon fiber are $32.28 \mathrm{Mpa}, 33.26 \mathrm{Mpa}, 50.28 \mathrm{Mpa}, 50.67 \mathrm{Mpa}$, and 50.87 Mpa. The 240 carbon fiber also has a bending strength value that tends to increase, with bending strength values as follows: three layers has a value of $21.21 \mathrm{Mpa}$, four layers has a value of $45.49 \mathrm{Mpa}$, five layers has a value of $59.65 \mathrm{Mpa}$, six layers has a value of 63.4 $\mathrm{MPa}$, and seven layers has a value of $71.7 \mathrm{MPa}$.

The results of the tensile test with type 220 carbon fiber have a tensile strength that tends to increase, with the following tensile strength values: three layers has a value of 58.92 Mpa, four layers has a value of $78.23 \mathrm{Mpa}$, five layers has a value of $90.71 \mathrm{Mpa}$, six layers has a value of 101.42 , and seven layers has a value of $225.5 \mathrm{Mpa}$. Carbon fiber type 240 also has a tensile strength value that tends to increase, with the following tensile strength values: three layers has a value of $90.44 \mathrm{Mpa}$, four layers has a value of $90.7 \mathrm{Mpa}$, five layers has a value of $190.56 \mathrm{Mpa}$, six layers has a value of $90.44 \mathrm{Mpa}$. the value is 228.71 , and seven layers has a value of $244.55 \mathrm{MPa}$.

The further research is expected to study in the process of making composites in avoiding the occurrence of air cavities that cause voids, because it can affect the strength of the composite material. The safety appliances are needed during the specimen composite test. It is because composite materials can cause irritation to the skin during the direct contact.

\section{REFERENCES}

1. P. Bhatt and A. Goe, "Carbon Fibres: Production, Properties and Potential Use," Mater. Sci. Res. India, vol. 14, no. 1, pp. 52-57, Jun. 2017, doi: 10.13005/msri/140109.

2. D. Laouchedi, B. Bezzazi, and C. Aribi, "Elaboration and characterization of composite material based on epoxy resin and clay fillers," J. Appl. Res. Technol., vol. 15, no. 2, pp. 190-204, Apr. 2017, doi: 10.1016/j.jart.2017.01.005.

3. X. Cai, C. Zhang, S. Zhang, Y. Fang, and D. Zou, "Application of carbon fibers to flexible, miniaturized wire/fiber-shaped energy conversion and storage devices," J. Mater. Chem. A, vol. 5, no. 6, pp. 2444-2459, 2017, doi: 10.1039/C6TA07868K.

4. I. Olofin and R. Liu, "The Application of Carbon Fibre Reinforced Polymer (CFRP) Cables in Civil Engineering Structures," Int. J. Civ. Eng., vol. 2, no. 7, pp. 1-5, Jul. 2015, doi: 10.14445/23488352/IJCE-V2I7P101.

5. H. Adam, "Carbon fibre in automotive applications," Mater. Des., vol. 18, no. 4-6, pp. 349-355, Dec. 1997, doi: 10.1016/S0261-3069(97)00076-9.

6. S. S. Kim, D. C. Park, and D. G. Lee, "Characteristics of carbon fiber phenolic composite for journal bearing materials," Compos. Struct., vol. 66, no. 1-4, pp. 359- 
366, Oct. 2004, doi: 10.1016/j.compstruct.2004.04.057.

7. H. Uematsu et al., "Mechanical behavior of unidirectional carbon fiber-reinforced polyamide 6 composites under transverse tension and the structure of polyamide 6 among carbon fibers," Polym. J., vol. 52, no. 10, pp. 1195-1201, Oct. 2020, doi: 10.1038/s41428-020-0371-4.

8. Y.-N. Liu, M. Li, Y. Gu, and Z. Zhang, "Characterization of torsion behavior and fracture morphology of single carbon fiber," J. Compos. Mater., vol. 48, no. 16, pp. 1993-1999, Jul. 2014, doi: 10.1177/0021998313493810.

9. S. M. Khajamoinuddin, A. Chatterjee, M. Bhat, D. Harursampath, and N. Gundiah, "Mechanical characterization of a woven multi-layered hyperelastic composite laminate under uniaxial loading," J. Compos. Mater., p. 002199832110115, Apr. 2021, doi: 10.1177/00219983211011528.

10. C. Yan, X. Song, H. Zhu, C. Jing, and S. Feng, "Flexural response of carbon fiber reinforced aluminum foam sandwich," J. Compos. Mater., vol. 52, no. 14, pp. 18871897, Jun. 2018, doi: 10.1177/0021998317735166.

11. F. Lionetto, A. Moscatello, G. Totaro, M. Raffone, and A. Maffezzoli, "Experimental and numerical study of vacuum resin infusion of stiffened carbon fiber reinforced panels," Materials (Basel)., vol. 13, no. 21, pp. 1-17, 2020, doi: 10.3390/ma13214800.

12. T. Gajjar, D. B. Shah, S. J. Joshi, and K. M. Patel, "Analysis of Process Parameters for Composites Manufacturing using Vacuum Infusion Process," Mater. Today Proc., vol. 21, pp. 1244-1249, 2020, doi: 10.1016/j.matpr.2020.01.112.

13. S. D. Salman, M. J. Sharba, Z. Leman, M. T. H. Sultan, M. R. Ishak, and F. Cardona, "Physical, Mechanical, and Morphological Properties of Woven Kenaf/Polymer Composites Produced Using a Vacuum Infusion Technique," Int. J. Polym. Sci., vol. 2015, pp. 1-10, 2015, doi: 10.1155/2015/894565.

14. S. Hofmann, B. Öztürk, D. Koch, and H. Voggenreiter, "Experimental and numerical evaluation of bending and tensile behaviour of carbon-fibre reinforced SiC," Compos. Part A Appl. Sci. Manuf., vol. 43, no. 11, pp. 1877-1885, Nov. 2012, doi: 10.1016/j.compositesa.2012.07.017.

15. J. Krystek, V. Laš, V. Pompe, and P. Hájková, "Tensile and bending test of carbon/epoxy and carbon/geopolymer composites after temperature conditioning," MATEC Web Conf., vol. 157, p. 05014, Mar. 2018, doi: 10.1051/matecconf/201815705014.

16. C. Santulli, "Mechanical and impact damage analysis on carbon/natural fibers hybrid composites: A review," Materials (Basel)., vol. 12, no. 3, 2019, doi: 10.3390/ma12030517.

17. A. Agirregomezkorta, M. Sánchez-Soto, G. Aretxaga, M. Sarrionandia, and J. Aurrekoetxea, "Effects of vacuum infusion processing parameters on the impact behavior of carbon fiber reinforced cyclic butylene terephthalate composites," $\mathrm{J}$. Compos. Mater., vol. 48, no. 3, pp. 333-344, Feb. 2014, doi: $10.1177 / 0021998312472218$.

18. M. C. Symington, O. S. David-west, W. M. Banks, J. L. Thomason, and R. A. Pethrick, "Vacuum Infusion of Natural Fibre Composites for Structural Applications."

19. P. Coronado, A. Argüelles, J. Viña, V. Mollón, and I. Viña, "Influence of temperature on a carbon-fibre epoxy composite subjected to static and fatigue loading under mode-I delamination," Int. J. Solids Struct., vol. 49, no. 21, pp. 2934-2940, Oct. 2012, doi: 10.1016/j.jijsolstr.2012.05.018.

20. A. Anvari, "Effect of Temperature on the Mechanical Properties of Carbon Composites," J. Eng., vol. 2020, pp. 1-16, Jul. 2020, doi: 10.1155/2020/8629471.

21. H. A. Al-Zubaidy, X. L. Zhao, and R. Al-Mahaidi, "Effect of Impact Tensile Load on Strength of CFRP Bonded Steel Plate Joints," Procedia Eng., vol. 14, pp. 1312-1317, 2011, doi: 10.1016/j.proeng.2011.07.165.

22. M. Tehrani, A. Y. Boroujeni, C. Luhrs, J. Phillips, and M. S. Al-Haik, "Hybrid composites 
JEMMME (Journal of Energy, Mechanical, Material, and Manufacturing Engineering)

based on carbon fiber/carbon nanofilament reinforcement," Materials (Basel)., vol. 7, no. 6, pp. 4182-4195, 2014, doi: 10.3390/ma7064182.

23. F. Vautard, P. Fioux, L. Vidal, J. Schultz, M. Nardin, and B. Defoort, "Influence of the carbon fiber surface properties on interfacial adhesion in carbon fiber-acrylate composites cured by electron beam," Compos. Part A Appl. Sci. Manuf., vol. 42, no. 7, pp. 859-867, Jul. 2011, doi: 10.1016/j.compositesa.2011.03.015. 